\title{
Viewpoint \\ Is reducing variability of blood glucose the real but hidden target of intensive insulin therapy?
}

\author{
Moritoki Egi ${ }^{1}$, Rinaldo Bellomo² and Michael C Reade ${ }^{2}$
}

1Department of Anesthesiology and Resuscitology, Okayama University Hospital, Shikata City, Japan 700-8558
2Department of Intensive Care, Austin Hospital, Melbourne, 145 Studley Road, Heidelberg, Victoria, Australia 3084

Corresponding author: Rinaldo Bellomo, rinaldo.bellomo@austin.org.au

Published: 6 April 2009

This article is online at http://ccforum.com/content/13/2/302

Critical Care 2009, 13:302 (doi:10.1186/cc7755)

(c) 2009 BioMed Central Ltd

\begin{abstract}
Since the first report that intensive insulin therapy reduced mortality in selected surgical critically ill patients, lowering of blood glucose levels has been recommended as a means of improving patient outcomes. In this initial Leuven trial, blood glucose control by protocol using insulin was applied to $98.7 \%$ of patients in the intensive group but to only $39.2 \%(P<0.0001)$ of patients in the control group. If appropriately applied, such protocols should decrease both the mean blood glucose concentration and its variability (variation of blood glucose concentration). Thus, it is logically possible that the benefit of intensive insulin therapy in the first Leuven trial was due to a decrease in mean glucose levels, a decrease in their variability, or both. Several recent studies have confirmed significant associations between variability of blood glucose levels and patient outcomes. Decreasing the variability of blood glucose levels might be an important dimension of glucose management, a possible mechanism by which an intensive insulin protocol exerts its putative beneficial effects, and an important goal of glucose management in the intensive care unit. Clinicians need to be aware of this controversy when considering the application of intensive insulin therapy and interpreting future trials.
\end{abstract}

\section{Intensive insulin therapy}

Acute hyperglycemia associated with insulin resistance is common in critically ill patients $[1,2]$, and control of blood glucose levels is considered important [3-6]. In the Leuven I trial, intensive insulin therapy (IIT) (target blood glucose levels of 4.4 to $6.1 \mathrm{mmol} / \mathrm{L}$ ) was reported to reduce mortality in selected surgical patients compared with conventional glycemic control $(P<0.04)$ (mean blood glucose level of $8.5 \mathrm{mmol} / \mathrm{L}$ ) [7]. In the Leuven II trial of medical critically ill patients, IIT failed to achieve a significant reduction in mortality on intention-to-treat analysis $(P=0.31)$ (Table 1) [8]. Using the pooled dataset of these two randomized controlled trials, IIT was associated with a reduction in mortality from
$23.6 \%$ to $20.4 \%(P=0.04)$. Furthermore, compared with a blood glucose level of 110 to $150 \mathrm{mg} / \mathrm{dL}$, mortality was higher with a blood glucose level of greater than $150 \mathrm{mg} / \mathrm{dL}$ (odds ratio $=1.38 ; P=0.007$ ) and lower with a level of less than $110 \mathrm{mg} / \mathrm{dL}$ (odds ratio $=0.77 ; P=0.02$ ) [9]. Subsequent investigations suggested that metabolic control, as reflected by normoglycemia, rather than any other effect of insulin was responsible for this effect [10]. Recently, lowering blood glucose levels has been recommended in international consensus guidelines as a means of improving patient outcomes [11,12]. However, in a multicenter randomized control trial among septic patients (VISEP [Efficacy of Volume Substitution and Insulin Therapy in Severe Sepsis] study), IIT had no significant effect on mortality $(P=0.74)$ [13] (Table 1). A recently published meta-analysis has also shown that, in critically ill adult patients, IIT is not associated with a significant reduction in hospital mortality but is clearly associated with an increased risk of hypoglycemia [14].

\section{Variability of glycemia in critically illness}

Blood glucose levels in critically ill patients vary markedly, even when using continuous feeding and insulin infusions [15]. Variability of glycemia is expressed as the magnitude of the fluctuation in glycemic control [16]. Even in the presence of the same mean value, the nature of glycemic control can be quite different in terms of variability (Figure 1a,b).

In three recently published IIT trials, an insulin protocol was applied to most of the patients in the IIT groups (about 98\%) (Table 1). If appropriately applied, such protocols should decrease both the mean blood glucose concentration and its variability. Contrary to this, there was no specific insulin protocol for patients in the control groups of such trials until

AUCpp = incremental area under the curve above mean pre-prandial glucose values; ICU = intensive care unit; IIT = intensive insulin therapy; MAGE = mean amplitude of glycemic excursion; MODD = mean of the daily difference in glucose; NICE-SUGAR = Normoglycemia in Intensive Care Evaluation-Survival Using Glucose Algorithm Regulation; VISEP = Efficacy of Volume Substitution and Insulin Therapy in Severe Sepsis. 
Table 1

Glycemia and mortality in three randomized controlled trials to assess the benefit of intensive insulin therapy

\begin{tabular}{|c|c|c|c|c|c|c|c|}
\hline & \multicolumn{2}{|c|}{ Glycemic control, $\mathrm{mmol} / \mathrm{L}^{\mathrm{a}}$} & \multicolumn{2}{|c|}{ Insulin protocol application } & \multicolumn{2}{|c|}{ Mortality } & \multirow[b]{2}{*}{$P$ value } \\
\hline & Conventional & IIT & Conventional & IIT & Conventional & IIT & \\
\hline Leuven I trial [7] & $8.5 \pm 1.8$ & $5.7 \pm 1.1$ & $\begin{array}{c}307 / 783 \\
(39.2 \%)\end{array}$ & $\begin{array}{l}755 / 765 \\
(98.7 \%)\end{array}$ & $\begin{array}{l}63 / 783 \\
(8.0 \%)\end{array}$ & $\begin{array}{c}35 / 765 \\
(4.6 \%)\end{array}$ & $<0.04$ \\
\hline Leuven II trial [8] & $8.5 \pm 1.7$ & $6.2 \pm 1.6$ & $\begin{array}{c}426 / 605 \\
(70 \%)\end{array}$ & $\begin{array}{c}580 / 595 \\
(98 \%)\end{array}$ & $\begin{array}{c}162 / 605 \\
(26.8 \%)\end{array}$ & $\begin{array}{l}144 / 595 \\
(24.2 \%)\end{array}$ & 0.31 \\
\hline VISEP study [13] & $8.4 \pm 1.8$ & $6.2 \pm 1.0$ & $\begin{array}{c}215 / 290 \\
(74.1 \%)\end{array}$ & $\begin{array}{c}243 / 247 \\
(98.4 \%)\end{array}$ & $\begin{array}{l}75 / 289 \\
(26.0 \%)\end{array}$ & $\begin{array}{l}61 / 247 \\
(24.7 \%)\end{array}$ & 0.74 \\
\hline
\end{tabular}

aGlycemic control values are presented as mean \pm standard deviation. IIT, intensive insulin therapy; VISEP, Efficacy of Volume Substitution and Insulin Therapy in Severe Sepsis.

glycemia exceeded 11.1 or $11.9 \mathrm{mmol} / \mathrm{L}$. In this setting, $61 \%$, $30 \%$, and $26 \%$ of patients in the conventional treatment arm did not appear to receive any protocol-based glycemic control in the Leuven I, Leuven II, and VISEP trials, respectively (Table 1). Such lack of protocol-based care might be logically expected to increase glycemic variability (Figure 1a) [15]. The rest of the conventional group patients who received an insulin protocol targeting a glycemia of between 10 and $11.1 \mathrm{mmol} / \mathrm{L}$ might have had a higher mean blood glucose concentration but less variability in glycemia (Figure 1b).

The Leuven I trial (surgical intensive care unit [ICU]) is currently the only study in which IIT reduced 28-day mortality on intention-to-treat analysis [7]. Interestingly, in the Leuven I study, the proportion of patients who were treated without the application of any glycemic control protocol was significantly higher compared with the other two major randomized trials of IIT $(P<0.0001)$. It is therefore possible that more Leuven I patients in the conventional treatment group had a greater degree of variability compared with the two later studies. This may explain why the dramatic results of the Leuven I study were not subsequently reproduced in other trials. Therefore, assessment of the variability of blood glucose levels might be necessary to fully understand the divergent results of these trials.

\section{Evidence that blood glucose variability affects outcome}

In 2006, we published the first study to assess the impact of variability of glycemia in critically ill patients. In this four-center retrospective study of 7,049 critically ill patients, we found that glycemic variability was an important dimension of glycemic control [16]. We used the standard deviation and the coefficient of variation of glycemia as markers of glycemic variability. We found that such variability was independently associated with ICU and hospital mortality rates as well as length of ICU stay. Most importantly, we found that glycemic variability predicted outcome better than mean blood glucose levels did.

\section{Figure 1}

(a)

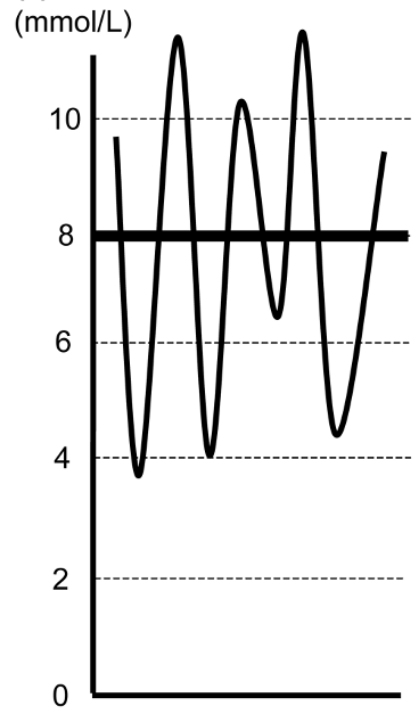

(b) (mmol/L)

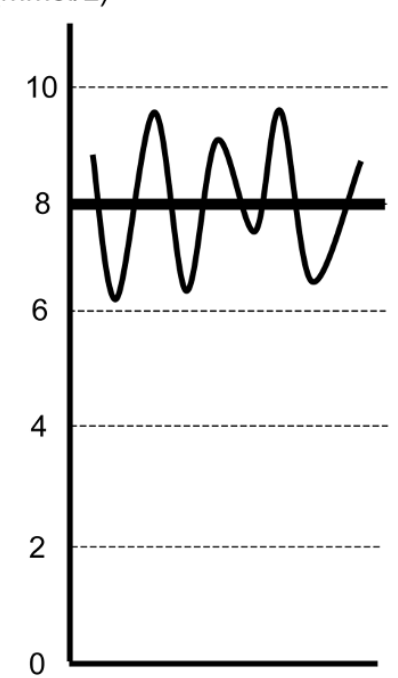

Graphic representations of glycemic control with a high mean glucose level and high (a) or low (b) variability.

Following our study, five other groups have also assessed the possible effect of variability of glycemia. In a single-center retrospective study of septic patients hospitalized for more than 1 day, Ali and colleagues [17] found, in a multivariate logistic regression analysis, that patients with an increased glycemic lability index, but lower average glucose values, had an increased risk of hospital mortality (odds ratio $=4.73$ ) compared with those with lower glycemic lability. These associations were not observed in patients with a high mean glucose level [17]. Hirshberg and colleagues [18] assessed the association of the variability of glycemia with mortality and morbidity in critically ill children admitted for more than 1 day in a pediatric ICU. The authors defined variability of glycemia as occurring in patients who experienced both hyperglycemia (blood glucose of greater than $8.4 \mathrm{mmol} / \mathrm{L}$ ) and hypoglycemia 
(blood glucose of less than $3.4 \mathrm{mmol} / \mathrm{L}$ ) during ICU stay. In this single-center retrospective study, increased variability was significantly associated with increased mortality, nosocomial infections, and hospital length of stay [18]. Dossett and colleagues [19] assessed the impact of glycemic variability on mortality in patients admitted to a surgical ICU. In this single-center retrospective study, standard deviation, percentile values, successive changes in blood glucose, and the triangular index (calculated by dividing the maximum sample density distribution of each histogram by the total number of each measurement) for various glucose-related indices were used as markers of glycemic variability. On univariate analysis, increased variability in glycemia was associated with increased mortality, whereas mean blood glucose concentration was not [19]. Waeschle and colleagues [20] assessed the relationship between glycemic variability and mortality in septic patients. In this single-center prospective study, standard deviations of blood glucose levels were used as markers of glycemic variability. A standard deviation of blood glucose levels of above $20 \mathrm{mg} / \mathrm{dL}$ was associated with a 9.6-fold increase of mortality compared with those with less than $20 \mathrm{mg} / \mathrm{dL}$. All patients with severe sepsis and septic shock who died had a standard deviation of blood glucose levels of above $20 \mathrm{mg} / \mathrm{dL}$ [20]. In a single-center retrospective observational study, Krinsley [21] found that mortality among patients with the lowest quartile of standard deviation of glucose levels, a surrogate of glycemic variability, was $12.1 \%$, increasing to $19.9 \%, 27.7 \%$, and $37.8 \%$ in the second, third, and fourth quartiles, respectively. The relationship between glycemic variability and mortality was strongest when mean blood glucose level was in the euglycemic range (70 to $99 \mathrm{mg} / \mathrm{dL}$ ). In this range, mortality in patients with high glycemic variability (fourth quartile with mortality of $30.1 \%$ ) was 5.1 times greater than in patients with low glycemic variability (first quartile with mortality of $5.9 \%$ [21]. Thus, all studies so far have confirmed that variability is associated with increased mortality and no studies have refuted this association.

\section{Possible glycemic variability indices in the critically ill}

So far, the standard deviation of glycemia $[16,18,20,21]$, the coefficient of variation of glycemia [16], the glycemic lability index [17], the percentile values for glycemia [19], successive changes in blood glucose [19], and the triangular index [19] have all been used as indices for variability of blood glucose levels during ICU stay. There are other possible measures for variability of glycemia which are used mainly in the chronic setting during management of diabetes. For example, the mean amplitude of glycemic excursion (MAGE) has been widely used as a glycemic variability index in diabetic patients [22]. MAGE is calculated as the arithmetic mean of blood glucose increases or decreases when both ascending and descending variations exceed the value of standard deviation of the blood glucose concentration in 24 hours. However, MAGE estimation requires the use of continuous glucose sensors [23] and is only suitable for assessment for patients with large variability. The incremental area under the curve above mean pre-prandial glucose values (AUCpp) have also been used in diabetic patients. The AUCpp has been used only in patients with intermittent parenteral feeding [24]. Thus, it is not suitable for critically ill patients requiring continuous enteral and/or parenteral feeding. The mean of the daily difference in glucose (MODD) is the absolute difference in mean blood glucose control during 24 hours [25]. MODD was measured using continuous glucose sensors and was used as an assessment tool for inter-day variability. Thus, it is also not suitable for the assessment of intra-day glycemic variability.

Only one study has compared the predictive value of several blood glucose indices. Ali and colleagues [17] calculated the standard deviation of glucose, the MAGEs, and the glycemic lability index. They found that the glycemic lability index had the best discrimination for mortality (area under the curve $=$ $0.67 ; P<0.001$ ) [17]. More studies are required to determine the best surrogate of glycemic variability in the ICU.

\section{Why is glycemic variability associated with worse outcomes?}

There are at least four possible explanations for the association between glycemic variability and outcome which we and others have observed. First, less glycemic variability may reflect more attention to detail in medical and nursing care, which may be the real determinants of better outcomes. Second, less glycemic variability may be associated with less severe illness. Third, glycemic variability might have a true deleterious biological effect in critically ill patients. Fourth, any combination of the above factors might apply.

There are studies to support the hypothesis that variations in glucose levels might have biological toxicity. Quagliaro and colleagues [26] have shown that, in umbilical vein cells, protein kinase C-beta, a surrogate of oxidative stress, was higher in the presence of fluctuations from hyperglycemia to normoglycemia when compared with sustained hyperglycemia. Monnier and colleagues [27] have shown that glycemic variability might trigger adverse biological events and oxidative stress in patients with type II diabetes. Such increased oxidative stress can result in endothelial dysfunction and contribute to vascular damage by triggering one of at least four major pathways: (a) enhanced polyol activity, causing sorbitol and fructose accumulation; (b) increased formation of advanced glycation end products; (c) activation of protein kinase $\mathrm{C}$ and nuclear factor-kappa-B; and (d) increased hexosamine pathway flux $[28,29]$. Furthermore, Watada and colleagues [30] and Azuma and colleagues [31] have shown that large glycemic variability enhances monocyte adhesion to endothelial cells in rats. Risso and colleagues [32] have shown that rapidly changing from hyperglycemia to normoglycemia causes increased apoptosis of human umbilical vein cells when compared with sustained hyperglycemia. 


\section{NICE-SUGAR trial}

The NICE-SUGAR (Normoglycemia in Intensive Care Evaluation-Survival Using Glucose Algorithm Regulation) trial is a large $(n=6,100)$ multicenter randomized controlled study of ITT [33] that has just completed recruitment. As the NICESUGAR trial compared two groups with a similar spread of target blood glucose values (IIT: 4.5 to $6.1 \mathrm{mmol} / \mathrm{L}$ versus control: 8 to $10 \mathrm{mmol} / \mathrm{L}$ ), this trial should make it possible to test the benefit of lowering the mean blood glucose concentration in a manner largely independent of the effects of IIT on glycemic variability. If there is a benefit from IIT, it would confirm that lowering the mean glucose level toward normoglycemia is a major mechanism behind the putative beneficial effects of IIT. If there is no difference in the outcomes of the ITT and control groups in NICE-SUGAR, it may be either that IIT is not effective or alternatively that, once glycemic variability is equivalent in both groups, the apparent beneficial effect of reducing mean blood glucose levels disappears. If IIT is shown to cause harm, it may be that, once variability is similarly reduced by having protocol-based care in both groups, the harmful effects of hypoglycemia become evident. The importance of understanding the mechanisms involved is great. If reducing variability of glycemia is the major biological mechanism underlying the putative benefit of IIT, it would not be necessary to intensively lower glucose levels (with the attending risk of hypoglycemia).

\section{Conclusions}

Tight glucose control might logically have one of two meanings: 'decreasing mean blood glucose concentrations' or 'decreasing variability in glycemia'. Decreasing the variability of blood glucose concentration might be an important dimension of glucose management, a possible mechanism by which applying the intensive insulin protocol exerted its putative beneficial effects, and an important goal of glucose management in the ICU. Clinicians need to be aware of this controversy when considering the application of IIT and interpreting future trials.

\section{Note}

This manuscript was submitted in early November 2008 prior to any knowledge of the NICE-SUGAR trial results, which were released by the New England Journal of Medicine on March 24, 2009. The authors note the following facts: the standard deviation (typical measure of variability) of glycemia in the IIT and Conventional treatment groups were essentially the same ( 25 versus $26 \mathrm{mg} / \mathrm{dL}$ ) while 206 patients in the IIT group experienced severe hypoglycemia compared to 15 in the conventional treatment group. Mortality was greater in the IIT group.

\section{Competing interests}

The authors declare that they have no competing interests.

\section{References}

1. Wolfe RR, Allsop JR, Burke JF: Glucose metabolism in man: responses to intravenous glucose infusion. Metabolism 1979,
28:210-220.

2. Shangraw RE, Jahoor F, Miyoshi H, Neff WA, Stuart CA, Herndon DN, Wolfe RR: Differentiation between septic and postburn insulin resistance. Metabolism 1989, 38:983-989.

3. Robinson LE, van Soeren $\mathrm{MH}$ : Insulin resistance and hyperglycemia in critical illness: role of insulin in glycemic control. AACN Clin Issues 2004, 15:45-62.

4. Coursin DB, Connery LE, Ketzler JT: Perioperative diabetic and hyperglycemic management issues. Crit Care Med 2004, 32(4 Suppl):S116-125.

5. Malmberg K, Ryden L, Efendic S, Herlitz J, Nicol P, Waldenstrom A, Wedel $H$, Welin L: Randomized trial of insulin-glucose infusion followed by subcutaneous insulin treatment in diabetic patients with acute myocardial infarction (DIGAMI study): effects on mortality at 1 year. $J A m$ Coll Cardiol 1995, 26:5765.

6. Malmberg K: Prospective randomised study of intensive insulin treatment on long term survival after acute myocardial infarction in patients with diabetes mellitus. DIGAMI (Diabetes Mellitus, Insulin Glucose Infusion in Acute Myocardial Infarction) Study Group. BMJ 1997, 314:1512-1515.

7. van den Berghe G, Wouters $P$, Weekers F, Verwaest C, Bruyninckx F, Schetz M, Vlasselaers D, Ferdinande P, Lauwers P, Bouillon R: Intensive insulin therapy in critically ill patients. $N$ Engl J Med 2001, 345:1359-1367.

8. Van den Berghe G, Wilmer A, Hermans G, Meersseman W, Wouters PJ, Milants I, Van Wijngaerden E, Bobbaers H, Bouillon $\mathrm{R}$ : Intensive insulin therapy in the medical ICU. $N$ Engl J Med 2006, 354:449-461.

9. Van den Berghe G, Wilmer A, Milants I, Wouters PJ, Bouckaert B, Bruyninckx $F$, Bouillon $R$, Schetz $M$ : Intensive insulin therapy in mixed medical/surgical intensive care units: benefit versus harm. Diabetes 2006, 55:3151-3159.

10. Van den Berghe G, Wouters PJ, Bouillon R, Weekers F, Verwaest C, Schetz M, Vlasselaers D, Ferdinande P, Lauwers P: Outcome benefit of intensive insulin therapy in the critically ill: insulin dose versus glycemic control. Crit Care Med 2003, 31:359366.

11. Dellinger RP, Carlet JM, Masur H, Gerlach H, Calandra T, Cohen J, Gea-Banacloche J, Keh D, Marshall JC, Parker MM, Ramsay G, Zimmerman JL, Vincent JL, Levy MM; Surviving Sepsis Campaign Management Guidelines Committee: Surviving Sepsis Campaign guidelines for management of severe sepsis and septic shock. Crit Care Med 2004, 32:858-873.

12. Dellinger RP, Levy MM, Carlet JM, Bion J, Parker MM, Jaeschke R, Reinhart K, Angus DC, Brun-Buisson C, Beale R, Calandra T, Dhainaut JF, Gerlach H, Harvey M, Marini JJ, Marshall J, Ranieri M, Ramsay G, Sevransky J, Thompson BT, Townsend S, Vender JS, Zimmerman JL, Vincent JL: Surviving Sepsis Campaign: international guidelines for management of severe sepsis and septic shock: 2008. Intensive Care Med 2008, 34:17-60.

13. Brunkhorst FM, Engel C, Bloos F, Meier-Hellmann A, Ragaller M, Weiler N, Moerer O, Gruendling M, Oppert M, Grond S, Olthoff D, Jaschinski U, John S, Rossaint R, Welte T, Schaefer M, Kern P, Kuhnt E, Kiehntopf M, Hartog C, Natanson C, Loeffler M, Reinhart K; German Competence Network Sepsis (SepNet): Intensive insulin therapy and pentastarch resuscitation in severe sepsis. N Engl J Med 2008, 358:125-139.

14. Wiener RS, Wiener DC, Larson RJ: Benefits and risks of tight glucose control in critically ill adults: a meta-analysis. JAMA 2008, 300:933-944.

15. Egi M, Bellomo R, Stachowski E, French CJ, Hart G, Stow P: Circadian rhythm of blood glucose values in critically ill patients. Crit Care Med 2007, 35:416-421.

16. Egi M, Bellomo R, Stachowski E, French CJ, Hart G: Variability of blood glucose concentration and short-term mortality in critically ill patients. Anesthesiology 2006, 105:244-252.

17. Ali NA, O'Brien J M Jr., Dungan K, Phillips G, Marsh CB, Lemeshow S, Connors AF Jr., Preiser JC: Glucose variability and mortality in patients with sepsis. Crit Care Med 2008, 36: 2316-2321.

18. Hirshberg $\mathrm{E}$, Larsen $\mathrm{G}$, Van Duker $\mathrm{H}$ : Alterations in glucose homeostasis in the pediatric intensive care unit: hyperglycemia and glucose variability are associated with increased mortality and morbidity. Pediatr Crit Care Med 2008, 9:361-366.

19. Dossett LA, Cao H, Mowery NT, Dortch MJ, Morris JM Jr., May AK: 
Blood glucose variability is associated with mortality in the surgical intensive care unit. Am Surg 2008, 74:679-685; discussion 685 .

20. Waeschle RM, Moerer O, Hilgers R, Herrmann P, Neumann $P$, Quintel M: The impact of the severity of sepsis on the risk of hypoglycaemia and glycaemic variability. Crit Care 2008, 12: R129.

21. Krinsley JS: Glycemic variability: a strong independent predictor of mortality in critically ill patients. Crit Care Med 2008, 36: 3008-3013.

22. Service FJ, Molnar GD, Rosevear JW, Ackerman E, Gatewood LC, Taylor WF: Mean amplitude of glycemic excursions, a measure of diabetic instability. Diabetes 1970, 19:644-655.

23. Monnier L, Colette C, Boegner C, Pham TC, Lapinski H, Boniface $\mathrm{H}$ : Continuous glucose monitoring in patients with type 2 diabetes: Why? When? Whom? Diabetes Metab 2007, 33:247252.

24. Zhou J, Jia W, Bao Y, Ma X, Lu W, Li H, Hu C, Xiang K: Glycemic variability and its responses to intensive insulin treatment in newly diagnosed type 2 diabetes. Med Sci Monit 2008, 14: CR552-558.

25. Wentholt IM, Kulik W, Michels RP, Hoekstra JB, DeVries JH: Glucose fluctuations and activation of oxidative stress in patients with type 1 diabetes. Diabetologia 2008, 51:183-190.

26. Quagliaro L, Piconi L, Assaloni R, Martinelli L, Motz E, Ceriello A: Intermittent high glucose enhances apoptosis related to oxidative stress in human umbilical vein endothelial cells: the role of protein kinase $\mathrm{C}$ and $\mathrm{NAD}(\mathrm{P}) \mathrm{H}$-oxidase activation. Diabetes 2003, 52:2795-2804.

27. Monnier L, Mas E, Ginet C, Michel F, Villon L, Cristol JP, Colette C: Activation of oxidative stress by acute glucose fluctuations compared with sustained chronic hyperglycemia in patients with type 2 diabetes. JAMA 2006, 295:1681-1687.

28. Brownlee M: Biochemistry and molecular cell biology of diabetic complications. Nature 2001, 414:813-820.

29. Brownlee M: The pathobiology of diabetic complications: a unifying mechanism. Diabetes 2005, 54:1615-1625.

30. Watada H, Azuma K, Kawamori R: Glucose fluctuation on the progression of diabetic macroangiopathy-new findings from monocyte adhesion to endothelial cells. Diabetes Res Clin Pract 2007, 77 Suppl 1:S58-61.

31. Azuma K, Kawamori R, Toyofuku Y, Kitahara Y, Sato F, Shimizu T, Miura K, Mine T, Tanaka Y, Mitsumata M, Watada H: Repetitive fluctuations in blood glucose enhance monocyte adhesion to the endothelium of rat thoracic aorta. Arterioscler Thromb Vasc Biol 2006, 26:2275-2280.

32. Risso A, Mercuri F, Quagliaro L, Damante G, Ceriello A: Intermittent high glucose enhances apoptosis in human umbilical vein endothelial cells in culture. Am J Physiol Endocrinol Metab 2001, 281:E924-930.

33. Bellomo R, Egi M: Glycemic control in the intensive care unit: why we should wait for NICE-SUGAR. Mayo Clin Proc 2005, 80:1546-1548. 